\title{
Isolated Radial Vein Thrombosis: Upper Extremity Deep Vein Thrombosis in a Patient With COVID-19 Infection
}

Sathishkumar Ramalingam ${ }^{1}$, Harkesh Arora ${ }^{1}$, Kulothungan Gunasekaran ${ }^{2}$, Maheswari Muruganandam ${ }^{3}$, Sivakumar Nagaraju 4

1. Hospital Medicine, Lovelace Medical Center, Albuquerque, USA 2. Pulmonary Critical Care, Yale New Haven Health Bridgeport Hospital, Bridgeport, USA 3. Rheumatology, University of New Mexico, Albuquerque, USA 4. Pulmonary Critical Care, Lovelace Medical Center, Albuquerque, USA

Corresponding author: Sathishkumar Ramalingam, sathishmed@gmail.com

\begin{abstract}
In general, upper extremity deep vein thrombosis (DVT) is less common than lower extremity DVT. Among upper extremity DVT cases, most of them are due to secondary causes like indwelling catheters, cancer, surgery, trauma or immobilization by plaster casts, pregnancy, oral contraceptives, and estrogen. Patients with coronavirus disease 2019 (COVID-19) infection are known to have coagulation dysfunction and a high incidence of DVT, mostly in the lower extremities; however, upper extremity DVT has been rarely reported. We present a rare case of upper extremity DVT in COVID-19 infection. A 56-year-old male with no significant past medical history was admitted with acute respiratory failure due to COVID-19 pneumonia. During hospitalization, he developed right upper extremity swelling, and an ultrasonogram showed right radial vein thrombosis. He was initially started on low molecular weight heparin (LMWH) and was discharged on apixaban. Patients with COVID-19 infection who develop DVT are recommended treatment with a direct oral anticoagulant (DOAC) for three months.
\end{abstract}

Review began 12/27/2020 Review ended 01/18/2021 Published 01/22/2021

\section{๑) Copyright 2021}

Ramalingam et al. This is an open access article distributed under the terms of the Creative Commons Attribution License CC-BY 4.0., which permits unrestricted use, distribution, and reproduction in any medium, provided the original author and source are credited.
Categories: Internal Medicine, Infectious Disease, Pulmonology

Keywords: covid-19, radial vein thrombosis, deep vein thrombosis (dvt), upper extremity thrombosis, covid coagulopathy, upper extremity dvt

\section{Introduction}

Deep vein thrombosis (DVT) is a complication of hospitalized patients due to less mobility and other underlying medical illness [1]. Patients with coronavirus disease 2019 (COVID-19) infection have a high incidence of DVT as they have coagulation abnormalities [2]. While upper extremity DVT is less common than lower extremity DVT, an isolated radial vein DVT is an extremely rare presentation. We present a case of a 56-year-old male admitted with acute respiratory failure due to COVID-19 infection and was found to have right radial vein thrombosis.

\section{Case Presentation}

A 56-year-old male with no significant past medical history presented with shortness of breath, cough, headache, and body pain for four days. His temperature was $98^{\circ} \mathrm{F}$, blood pressure was $142 / 91 \mathrm{mmHg}$, heart rate $92 / \mathrm{min}$, and oxygen saturation was $88 \%$ on room air. His white blood cell was $5.1 \mathrm{~K} / \mathrm{uL}$, platelet 122 $\mathrm{K} / \mathrm{uL}$, D-Dimer was $476 \mathrm{ng} / \mathrm{mL}$, ferritin $2184 \mathrm{ng} / \mathrm{mL}$, erythrocyte sedimentation rate (ESR) $45 \mathrm{~mm} / \mathrm{hr}$, and Creactive protein (CRP) $27 \mathrm{mg} / \mathrm{dL}$. Chest X-ray revealed bilateral infiltrates. Reverse transcription-polymerase chain reaction detected severe acute respiratory syndrome coronavirus 2 (SARS-CoV-2) via a nasopharyngeal swab and he was admitted to the hospital. Peripheral venous access was obtained on the left forearm and was he started on remdesivir and dexamethasone. He was placed on low molecular weight heparin (LMWH) $0.5 \mathrm{mg} / \mathrm{kg}$ every 12 hours for DVT prophylaxis. He developed acute respiratory failure requiring $15 \mathrm{~L}$ of oxygen and did not require high flow oxygen or non-invasive positive pressure ventilation (NIPPV). On day six of hospitalization, he developed right upper extremity swelling, and D-Dimer was $4674 \mathrm{ng} / \mathrm{dL}$. Bilateral venous Doppler ultrasound of the upper extremity showed acute DVT within the right proximal radial vein (Figure 1). Lower extremity doppler ultrasound was unremarkable for any DVT. Computed tomography (CT) scan of the chest with contrast showed bilateral ground-glass opacities and no pulmonary embolism (PE). He was started on $1 \mathrm{mg} / \mathrm{kg}$ of enoxaparin (therapeutic dose) every 12 hours, subsequently switched to oral apixaban. His oxygen demand improved, and he was discharged home with 3 liters of oxygen and apixaban. 


\section{Cureus}

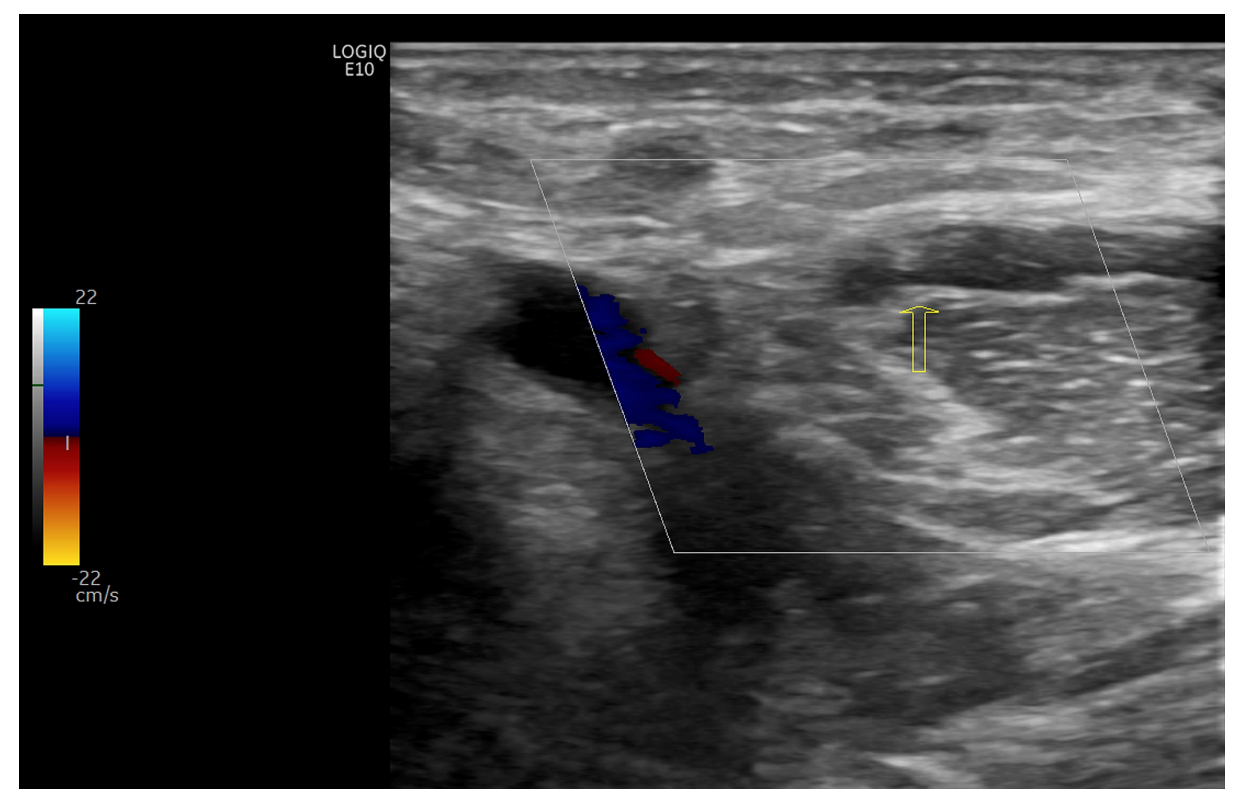

\section{FIGURE 1: Venous duplex of the bilateral upper extremities}

Deep vein thrombus noted within the right proximal radial vein.

\section{Discussion}

DVT is one of the complications of hospitalized patients who are bedridden with multiple medical problems. Upper extremity DVT is less common but still accounts for $5 \%-10 \%$ of all DVT cases, mostly associated with the intravenous catheter [3]. The most common anticoagulants used for DVT prophylaxis are enoxaparin and heparin. Mechanical prophylaxis includes graduated compression stockings (GCS) and intermittent pneumatic compression (IPC) devices [4]. Coagulation abnormalities have been noted in patients with COVID-19, and their exact mechanism is not well understood. The role of COVID-19 on the angiotensinconverting enzyme 2 receptors on endothelial cells and cytokine storm has been found to play a role in thromboembolic complications [5]. Patients with COVID-19 infection with increased D-Dimer, low platelets, and prolonged prothrombin time on initial presentation have a high risk of developing venous thromboembolism (VTE) and disseminated intravascular coagulation (DIC) [6,7]. Thrombotic events, including PE, DVT, myocardial infarction (MI), and a cerebrovascular accident, have been reported in patients with COVID-19 infection [8,9]. There are only a few upper extremity DVT reported in patients with COVID-19 infection [10]. Isolated radial vein thrombosis is an exceedingly rare presentation, and no case has been reported in patients with COVID-19 infection. Patients hospitalized with COVID-19 infection have a high risk of developing VTE and should be started on standard anticoagulation thromboprophylaxis (LMWH every 12 hours). Our patient developed DVT despite being on prophylactic anticoagulation. Patients with proximal DVT need to be started on LMWH or intravenous unfractionated heparin or direct oral anticoagulants (DOAC) like apixaban or rivaroxaban [11]. Patients with upper extremity DVT involving proximal vein should be treated with oral anticoagulation, and there is no benefit from thrombolytic therapy. The recommended treatment and duration for a patient with upper extremity DVT is a DOAC for at least three months unless otherwise contraindicated [12].

\section{Conclusions}

The incidence of VTE in COVID-19 patients is higher than in the general population, even if they receive prophylactic anticoagulation. There must be high suspicion of DVT in patients with COVID-19 as timely treatment with anticoagulation can prevent life-threatening PE. Even though upper extremity DVT is less common, clinicians should be vigilant in screening COVID-19 patients as there will be significant comorbidities associated with it.

\section{Additional Information}

\section{Disclosures}

Human subjects: Consent was obtained by all participants in this study. Conflicts of interest: In compliance with the ICMJE uniform disclosure form, all authors declare the following: Payment/services info: All authors have declared that no financial support was received from any organization for the submitted work. Financial relationships: All authors have declared that they have no financial relationships at present or within the previous three years with any organizations that might have an interest in the submitted work. Other relationships: All authors have declared that there are no other 


\section{References}

1. Khalafallah AA, Kirkby BE, Wong S, et al.: Venous thromboembolism in medical patients during hospitalisation and 3 months after hospitalisation: a prospective observational study. BMJ Open. 2016, 6:e012346. 10.1136/bmjopen-2016-012346

2. Levi M, Thachil J, Iba T, Levy JH: Coagulation abnormalities and thrombosis in patients with COVID-19 . Lancet Haematol. 2020, 7 :e438-e440. 10.1016/S2352-3026(20)30145-9

3. Upper extremity deep vein thrombosis. (2017). Accessed: December 10, 2020: https://www.acc.org/latestin-cardiology/articles/2017/11/09/13/30/upper-extremity-deep-vein-thrombosis.

4. Gaspard D, Vito K, Schorr C, Hunter K, Gerber D: Comparison of chemical and mechanical prophylaxis of venous thromboembolism in nonsurgical mechanically ventilated patients. Thrombosis. 2015, 849142 . $10.1155 / 2015 / 849142$

5. Kander T: Coagulation disorder in COVID-19. Lancet Haematol. 2020, 7:E630-E632. 10.1016/S23523026(20)30218-0

6. Al-Samkari H, Karp Leaf RS, Dzik WH, et al.: COVID-19 and coagulation: bleeding and thrombotic manifestations of SARS-CoV-2 infection. Blood. 2020, 136:489-500. 10.1182/blood.2020006520

7. Lazzaroni MG, Piantoni S, Masneri S, et al.: Coagulation dysfunction in COVID-19: the interplay between inflammation, viral infection and the coagulation system. Blood Rev. 2020, 24:100745.

10.1016/j.blre.2020.100745

8. Bilaloglu S, Aphinyanaphongs Y, Jones S, Iturrate E, Hochman J, Berger JS: Thrombosis in hospitalized patients with COVID-19 in a New York City health system. JAMA. 2020, 324:799-801. 10.1001/jama.2020.13372

9. Gunasekaran K, Amoah K, Rajasurya V, Buscher MG: Stroke in a young COVID-19 patient. QJM. 2020, 113:573-574. 10.1093/qjmed/hcaa177

10. Marone EM, Rinaldi LF: Upsurge of deep venous thrombosis in patients affected by COVID-19: preliminary data and possible explanations. J Vasc Surg Venous Lymphat Disord. 2020, 8:694-695. 10.1016/j.jvsv.2020.04.004

11. Moores LK, Tritschler T, Brosnahan S, et al.: Prevention, diagnosis, and treatment of VTE in patients with coronavirus disease 2019: CHEST guideline and expert panel report. Chest. 2020, 158:1143-1163. 10.1016/j.chest.2020.05.559

12. Kearon C, Akl EA, Ornelas J, et al.: Antithrombotic therapy for VTE disease: CHEST guideline and expert panel report. Chest. 2016, 149:315-352. 10.1016/j.chest.2015.11.026 